\title{
A Study on the Needs for Career Decision and Curriculum Improvement of Military-Specialized High School Students
}

\section{군(軍)특성화고 학생의 진로 선택 및 교육과정 개선 요구도 연구}

Soo-Jeong Lee ${ }^{1}$, Yun-Jeong Kim²

이수정 ${ }^{1}$, 김윤정 2

${ }^{I}$ Senior Research Fellow, Korea Research Institute for Vocational Education \& Training, Republic of Korea, crystal@krivet.re.kr

${ }^{2}$ Professor, Dep. Health, Counselling and Welfare, Hanseo University, Republic of Korea, twoyun21@hanmail.net

Corresponding author: Yun-Jeong Kim

\begin{abstract}
The purpose of this study is to find the influential factors of Military-specialized high school students on their career decision, and their needs for curriculum improvement, and thereby to propose an improvement plan. To this end, the researcher conducted a survey with 747 Military-specialized high school students. The data gathered from the survey were used for frequency analysis, t-test, and oneway ANOVA in SPSS Win 25.0. The results revealed that their career decision was highly influenced by teachers and parents. The motives for such a decision were to become a professional soldier, and to hope for occupational stability. Of the students, $68.3 \%$ wanted to work as a non-commissioned officer for a long time and then get discharged after their graduation. Their career satisfaction scored high at 4.05. Regarding career needs, teachers' offering of detailed information, secured occupational stability of non-commissioned officer, expansion of additional points for being appointed as a noncommissioned officer with long-term service, and fast track for an on-commissioned officer with longterm service were highly needed. With regard to needs for curriculum improvement, highly needed were operation of the curriculum specialized in line with the selection of long-term service, organization of the curriculum for enhancing competency in military specialties in association with the characteristics of local militaries, enhancement of professional subjects for raising advanced science \& technology based soldiers, and the curriculum for enhancing relations between specialties and military service areas. Based on these findings, this study proposed a plan for supporting the career design of Militaryspecialized high school students and improving the quality of their curriculum.
\end{abstract}

Keywords: Military-specialized High School, Influential Factors of Career Decision, Career Needs, Curriculum Improvement Needs

요약: 본 연구는 군(軍) 특성화고등학교(이하 '군특성화고) 학생들의 진로 선택과 교육과정 개선 요구도를 파악하고 개선 방안을 제안함에 연구의 목적을 두었다. 이를 위해 이수정

Received: August 12, 2021; 1st Review Result: September 29, 2021; 2nd Review Result: November 15, 2021 Accepted: December 31, 2021

*본 연구는 이수정, 허영준, 이미란, 송기원, 김윤정, 박상혁(2021)의 '군특성화고 운영 개선방안 연구. 한국직업능력연구원.한국장학재단'의 일부를 보완하였다. 
외[1]의 데이터 중 군특성화고 재학생 데이터만을 선별하여 사용하였다. 설문 결과는 SPSS Win 25.0을 이용하여 빈도 분석, t-test, oneway ANOVA를 적용하였다. 연구 결과 첫째, 군특성화고 학생들은 2학년 때 군특성화고(반)을 선택하는 비율이 $54.5 \%$ 로 가장 많았고, 진로 선택 시 선행연구 결과와 같이 교사, 부모의 영향을 많이 받는 것으로 나타났다. 그리고 군특성화고를 선택한 동기는 직업군인으로 직업적 안정성을 확보가 $73.7 \%$ 로 매우 높게 나타났다. 둘째, 군특성화 재학생들의 진로 만족도는 4.05로 매우 높았으며, 진로 선택과 관련해서 교사의 상세한 사전정보 제공, 부사관의 직업적 안정성, 장기부사관 임관 시 가산점 확대 및 패스트트랙 도입 등에 대한 요구도가 높았다. 셋째, 교육과정 개선과 관련해서 장기복무 선발 기준에 맞춰 특화된 교육과정, 지역군의 특성과 연계한 군 특기 분야 역량 강화, 첨단과학기술병 양성 위한 전문교과 강화, 주특기와 군복무 분야의 연계성 강화 등에 대한 요구도가 높은 것으로 나타났다. 이를 기반으로 군 특성화고 학생들의 졸업 후 진로 설계를 지원할 수 있는 군특성화고 교육과정 운영 개선 방안을 제안하였다.

핵심어: 군(軍)특성화고, 진로 선택 영향 요소, 진로 선택 요구도, 교육과정 개선 요구도

\section{1. 서론}

최근 인구절벽 심화와 군복무 단축 등의 문제로 병역자원 부족에 대한 문제가 제기됨에 따라 정부는 「직업계고 취업지원 방안」(2021.7.7)을 통해 군특성화고등학교 (이하 ‘군특성화고'라 함) 출신의 군복무 중 지속적인 경력숙련 지원, 우수기술병에 대해서는 방산업체 취업 지원 등의 방안을 발표하였다[2].

군특성화고를 통해 양성된 부사관들은 임무 수행면에서, 간부로서 자질면에서 다른 양성 과정보다 군에서 요구하는 우수한 역량을 함양할 것으로 그 기대가 높아 2008년 10 개교(19학급)로 시작하여, 2021년 현재 43개교(73학급)로 운영되는 등 양적으로 확대되었다. 한편, 국방부는 10 년간 군특성화고를‘유급지원병’제도를 운영하는 과정에서 발생한 문제점을 보완하기 위하여 2020년 12월「병역법」[법률 제17684호, 2020.12.22., 일부개정]을 통해‘유급지원병 제도'를 폐지하고 단기하사로서의 신분에 부합하는 명칭 부여, 직업적 안정성 보장 등을 위해 장기복무 기회 부여 등 개선 방안을 명시하여 ‘임기제 부사관제’로 개정하였다[3].

그럼에도 불구하고 학교 현장에서는 여전히 현재 교육과정으로는 전문성 함양을 위한 절대적 시수 부족, 졸업 후 안정적 직업군인으로 진출의 어려움, 군특성화고 이외에 다른 특성화고에서 민간부사관학과가 운영됨에 따라 부사관 양성 통로가 확대되는 등 여러 가지 한계점이 제기되고 있다[1][4]. 따라서, 숙련된 전문병 및 기술부사관을 육성이라는 군특성화고의 정체성 관점에서 교육과정의 질 제고를 통한 경쟁력 확보가 매우 시급한 상황이다

군특성화고와 관련된 선행연구[1][5][6]는 주로 군특성화고 제도를 개선하는 정책 연구가 이루어왔으며, 군특성화고 학생을 대상으로 진로 또는 교육과정에 대한 요구를 살펴보면 연구는 거의 이루어지지 않았다. 또한, 특성화고 학생을 대상으로 한 진로 관련 연구[7-10]는 주로 특성화고 학생 전체 또는 계열별로 이루어졌는데 특성화고 선택에 대한 영향을 주는 변인을 탐색하고, 학생 또는 학부모 대상의 구체적인 진로나 직업 정보 제공이 필요성을 제안하였다. 그리고 특성화고 학생들이 산업계에서 요구하는 
역량을 함양하기 위해서는 학교 교육(이론)과 학교 밖 교육(실습) 등이 연계된 교육과정으로의 변화가 필요함을 강조하였다[2][5][8][11][12].

따라서 본 연구에서는 군특성화고 학생 대상으로 진로 선택에 영향을 주는 요소, 그리고 진로 선택과 교육과정 개선을 위한 요구도는 무엇인지를 살펴보고자 한다. 이를 통해 군특성화고 교육과정 개선을 통해 군특성화고-군으로 이행하는 데 있어 미스매치를 최소화하고, 전역 후 군에서 축적된 기술과 연관되는 분야로 취업할 수 있는 역량을 함양하는 방안을 마련할 수 있을 것으로 기대한다.

\section{2. 선행연구 고찰}

\section{1 군특성화고 교육과정 편성 및 운영 지침}

국방부/교육부는 「특성화고 육성 전략」으로 군에서 필요한 특수인력 양성이 가능한 학교를 2008년부터 군특성화고로 지정하였다[13]. 2021년 43개교(73학급)에서 운영되고 있는 전공은 주로 기계과, 정보/통신과, 전기/전자과, 건설과, 재로, 화학공업과에 해당한다. 그리고 1,2 학년때는 다른 학생들과 동일한 교육과정을 이수하고, 3학년부터 군특성화반 교육과정을 이수하게 된다. 특히, 3학년(1년 과정) 교육과정은 전문교과 과정과 현장 체험학습(실습, 군 위탁 교육)으로 운영하는데, 주 12 시간 내에서 군맞춤형 교육, 군 관련 국가기술 자격증 취득, 부대 방문 체험, 첨단장비 기술교육 등의 과정을 이수하게 된다. 다만, 1.2학년 과정은 학교별로 자율과정으로 운영할 수 있는데, 주 2시간 내 자율로 전공기초 교육(각 군 병과 교육)과 특기, 적성교육, 태권도와 인성/리더십 등을 학습하게 된다.

\section{2 특성화고 학생의 진로 선택 영향 요인 및 교육과정 개선 요구 관련 선행연구}

\subsection{1 특성화고 학생의 진로 선택 및 진로 만족도, 진로 관련 요구도}

강민수[14]는 특성화고에서 학생이 진로를 결정할 때, 교사가 중요한 가이드 역할을 하는 것과 주로 학부모의 영향을 받는 것을 확인하였고, 안재영[8]은 군특성화고와 유사한 방식(학교와 기업 교육을 동시에 실시)인 도제교육 선택 시 영향을 준 사람으로는 자기 자신(63.9\%), 담임교사 $(12.8 \%)$, 전문교과 교사 $(8.3 \%)$, 부모님(8.1\%)이라고 하였다. 그리고, 오석영[10]은 진로 미결정 학생들의 경우 가정에서의 부모님의 진로 결정에 의존하는 경향을 보인다고 하였다. 이명훈[9]은 특성화고 학생들의 직업 정보 부족은 진로 결정에 매우 부정적인 영향을 주므로 학생들의 유용한 직업 정보와 함께 다양한 진로 교육 기회 제공의 필요성을 제안하였다. 그리고 이찬주[11]는 특성화고 학생들은 취업 및 현장실습 업체 소개 및 매칭 $(26.5 \%)$, 자격증 취득을 위한 교육 $(25 \%)$, 자기소개서 및 면접 지도(19.9\%), 선배와 멘토-멘티 매칭(9.6\%), 대학 진학에 대한 안내(7.2\%), 취업 후 경력개발을 위한 실질적인 안내(6.8\%) 등을 원하고 있다고 하였다.

\subsection{2 특성화고 학생의 교육과정 개선 요구 관련 연구}

이찬주[11]는 특성화고 학생들은 보통교과 수업 만족도는 3.68점(5점 만점), 전문교과 수업에 대한 만족도는 3.78(5점 만점)로 보통 교과에 비해 상대적으로 높음을 확인하였고, 학생들은 교육과정 편성 시 전문교과 수업 시간의 확대를 희망한다고 밝혔다. 그리고 
이수정 외[1]은 기업 내 교육의 실제 업무와의 연계, 기업 내 교육 시 실습 기회 제공, 기업 현장 교사의 교육 훈련 내용에 대한 전문성 등 학교와 기업 간 교육의 연계가 중요함을 강조하였다. 그리고 안재영[8]은 전공 직무 교육인 Off-JT와 OJT 이외에도 학생의 진로 결정에 필요한 다양한 체험활동이 필요성을 제안하였다.

선행연구 고찰을 통한 시사점은 다음과 같다. 첫째, 특성화고 학생들은 특성화고를 선택할 때 교사 또는 학부모의 영향을 많이 받으므로 중학교 학부모 대상 진로 교육 프로그램 개발이 필요하다. 둘째, 학생들이 특성화고에 입학하기 전 특성화고에 대한 정보(교육과정, 졸업 후 진로 등)가 부족할 때 진로 결정에 매우 부정적인 영향을 주므로 다양한 정보를 제공할 필요가 있다. 셋째, 이론과 실습을 병행하는 교육과 자신의 적성을 탐색하고 진로를 결정하는 데 도움을 주는 다양한 프로그램 운영이 필요함을 알 수 있다.

\section{3. 연구방법}

\section{1 자료 수집 절차 및 연구 대상 특징}

본 연구에서는 이수정 외[1]가 군특성화고 43개교 3학년 재학생을 대상으로 하여 2020년 12월 2021년 2월까지 실시한 설문조사 데이터를 활용하였다. 2020년 기준으로 전체 군특성화고 학생 1,195 명 중 성실하게 응답한 747 명 $(62.5 \%)$ 의 결과를 분석에 활용하였다. 연구 대상자의 학교 소재지는 수도권이 $30.9 \%$, 학과는 기계과가 $43.9 \%$ 로 가장 많고, 주특기는 정보통신인 경우가 $34.5 \%$ 로 가장 많고, 응답자의 $82.3 \%$ 는 주특기 관련 자격증을 가지고 있었다.

\section{2 측정 도구}

본 연구에서 사용된 측정 도구는 [표 1]과 같이 구성하였으며, 이수정 외[1]에서 개발한 설문 문항 중 재학생이 응답한 문항을 활용하였다.

[표 1] 측정도구

[Table 1] Measurement

\begin{tabular}{c|l}
\hline \multicolumn{1}{c|}{ 구분 } & \multicolumn{1}{c}{ 문항 } \\
\hline 군특성화고진로선택에 영향을 주는 요소 & $\begin{array}{l}\text { 군특성화고 선택 시기 : 선택형 문항 (1문항) } \\
\text { 군특성화고 선택에 영향을 준 사람 : 선택형 문항 (1문항) } \\
\text { 군특성화고 진로선택동기 :선택형 문항 (1문항) } \\
\text { 졸업 후 진로계획 : 선택형 문항 (1문항 }\end{array}$ \\
\hline 진로만족도 및 진로개선 요구도 & $\begin{array}{l}\text { 진로만족도 : } 5 \text { 점 리커트 척도 문항(1문항) } \\
\text { 진로 개선 요구도 관련 : } 5 \text { 점 리커트 척도 문항(4문항) }\end{array}$ \\
\hline 교육과정 개선 요구도 & $\begin{array}{l}\text { 교육과정 개선 요구도 관련 : 5점 리커트 척도 문항(4문항) } \\
\text { 향후 필요한 전문교과 : 선택형 문항(1문항) }\end{array}$ \\
\hline
\end{tabular}

출처: 이수정 외(2021).

\section{3 통계 분석 방법}

본 연구목적을 달성하기 위해 SPSS Win 25.0을 이용하여 빈도분석, t-test, oneway 
ANOVA를 적용하였다.

\section{4. 연구 결과}

\section{1 군특성화고 학생의 진로 선택 영향 요인 및 진로 개선 요구도}

\subsection{1 군특성화고 학생의 진로 선택 영향 요소와 진로 계획}

군특성화고 학생의 진로 선택에 영향을 주는 요소 중 선택 시기는 고등학교 2학년이 $54.4 \%$ 로 가장 많았으며, 선택에 영향을 주는 사람은 부모님(41.8\%), 군특성화고 교사(23.5\%), 담임/부장교사(19.4\%)로 나타났다. 그리고 군특성화고를 선택하게 된 동기는 직업군인이 되고 싶어서(38.1\%), 직업적 안정성(35.6\%)이 높은 비율을 차지하였으며, 학생들은 졸업 후 장기복무를 희망하는 비율이 $68.3 \%$ 로 매우 높게 나타났다.

\subsection{2 군특성화고 학생의 진로 만족도}

군특성화고 진로 만족도에 대한 문항 중 학생의 특성 변인 중 통계적으로 유의미한 차이를 보인 문항인 학생의 주특기, 주특기 관련 자격증 소지 여부에 따른 분석 결과는 [표 2]와 같다. 군특성화고 학생의 진로 만족도는 4.05로 매우 높았으며, 주특기, 자격증 소지 여부에 따라 진로 만족도에 통계적으로 유의미한 차이가 있는 것으로 나타났다.

[표 2] 군특성화고 학생의 진로 만족도 <n=747>

[Table 2] Career Satisfaction of Military-specialized High Schools Students

\begin{tabular}{|c|c|c|c|c|c|c|}
\hline \multirow{2}{*}{\multicolumn{2}{|c|}{ 구분 응답 }} & \multirow{2}{*}{ 사례수 } & \multicolumn{2}{|c|}{ 5점 } & \multirow{2}{*}{$\mathrm{F}$ 값 } & \multirow{2}{*}{ Scheffe } \\
\hline & & & 평균 & 표준편차 & & \\
\hline \multicolumn{2}{|c|}{ 전체 } & 747 & 4.05 & 1.003 & & \\
\hline \multirow[t]{4}{*}{ 주특기 } & 정보통신 & 258 & 4.02 & 0.968 & \multirow[t]{4}{*}{$7.436^{* * *}$} & $\mathrm{~b}$ \\
\hline & 기계정비 & 141 & 4.11 & 1.015 & & $\mathrm{~b}$ \\
\hline & 항공 & 115 & 3.70 & 1.164 & & $\mathrm{a}$ \\
\hline & 기타 & 233 & 4.22 & 0.905 & & $\mathrm{~b}$ \\
\hline \multirow[t]{4}{*}{ 자격증 } & 있음 & 615 & 4.09 & 0.976 & \multirow[t]{4}{*}{$5.700^{* *}$} & $\mathrm{~b}$ \\
\hline & 준비 중 & 71 & 4.01 & 1.035 & & $\mathrm{~b}$ \\
\hline & 준비 예정 & 45 & 3.96 & 0.999 & & $\mathrm{~b}$ \\
\hline & $\begin{array}{c}\text { 취득의향 } \\
\text { 없음 }\end{array}$ & 16 & 3.06 & 1.436 & & $\mathrm{a}$ \\
\hline
\end{tabular}

${ }^{* *} \mathrm{p}<.01,{ }^{* * *} \mathrm{p}<.001$

구체적으로 살펴보면 주특기에 따라서는 항공 주특기인 군특성화고 학생의 진로 만족도가 낮게 나타났다. 그리고 자격증 소지 유무와 관련해서는 자격증을 취득할 의향이 없는 군특성화고 학생의 진로 만족도가 다른 학생들(주특기 관련 자격증이 있거나 준비 중이거나 준비 예정인 학생)에 비해 낮은 것으로 나타났다. 특히 주특기가 항공 분야인 경우, 주특기 관련 자격증을 취득할 의향이 없는 군특성화고 학생이 낮게 나타났으므로 이에 대한 맞춤형 진로 지도 또는 상담이 필요함을 알 수 있다. 


\subsection{3 군특성화고 학생의 진로 개선 요구도}

군특성화고 진로 개선 요구도에 대한 문항 중 학생의 일반특성 변인 중 통계적으로 유의미한 차이를 보인 학생의 주특기 관련 자격증 소지 여부에 따른 분석 결과는 [표 3]과 같다.

[표 3] 군특성화고 학생의 진로 개선 요구도<n=747>

[Table 3] Career Improvement Needs of Military-specialized High Schools Students

\begin{tabular}{|c|c|c|c|c|c|c|c|}
\hline \multirow{2}{*}{\multicolumn{2}{|c|}{ 설문 문항 응답 }} & \multirow{2}{*}{$\begin{array}{l}\text { 구분(자격증 } \\
\text { 소지여부) }\end{array}$} & \multirow{2}{*}{ 사례수 } & \multicolumn{2}{|c|}{ 5점 } & \multirow{2}{*}{$\mathrm{F}$ 값 } & \multirow{2}{*}{ Scheffe } \\
\hline & & & & 평균 & 표준편차 & & \\
\hline \multirow{7}{*}{$\begin{array}{l}\text { 진 } \\
\text { 로 }\end{array}$} & \multirow{4}{*}{$\begin{array}{c}\text { 교사의 군복무 및 향후 } \\
\text { 진로관련 상세한 사전 } \\
\text { 정보 제공 }\end{array}$} & 있음 & 615 & 3.91 & 0.998 & \multirow{4}{*}{$3.772^{*}$} & $\mathrm{~b}$ \\
\hline & & 준비 중 & 71 & 3.69 & 1.022 & & $\mathrm{ab}$ \\
\hline & & 준비 예정 & 45 & 3.98 & 0.812 & & $\mathrm{~b}$ \\
\hline & & 취득의향 없음 & 16 & 3.19 & 1.377 & & $\mathrm{a}$ \\
\hline & \multirow{4}{*}{$\begin{array}{c}\text { 부산관의 직업적 } \\
\text { 안정성 확보 }\end{array}$} & 있음 & 615 & 4.21 & 0.906 & \multirow{4}{*}{$4.391^{* *}$} & $\mathrm{~b}$ \\
\hline & & 준비 중 & 71 & 3.97 & 1.042 & & $\mathrm{ab}$ \\
\hline & & 준비 예정 & 45 & 4.13 & 0.786 & & $\mathrm{~b}$ \\
\hline \multirow{2}{*}{$\begin{array}{l}\text { 개 } \\
\text { 선 }\end{array}$} & & 취득의향 없음 & 16 & 3.50 & 1.366 & & a \\
\hline & \multirow{4}{*}{$\begin{array}{l}\text { 장기부사관 임관 시 } \\
\text { 가산점 확대 }\end{array}$} & 있음 & 615 & 4.20 & 0.906 & \multirow{4}{*}{$4.875^{* *}$} & $\mathrm{~b}$ \\
\hline \multirow{7}{*}{$\begin{array}{l}\text { 요 } \\
\text { 구 } \\
\text { 도 }\end{array}$} & & 준비 중 & 71 & 3.97 & 0.956 & & $\mathrm{ab}$ \\
\hline & & 준비 예정 & 45 & 4.11 & 0.775 & & $\mathrm{~b}$ \\
\hline & & 취득의향 없음 & 16 & 3.44 & 1.209 & & $\mathrm{a}$ \\
\hline & \multirow{4}{*}{$\begin{array}{c}\text { 장기복무 } \\
\text { 부사관 패스트트랙 }\end{array}$} & 있음 & 615 & 4.31 & 0.836 & \multirow{4}{*}{$3.965^{* *}$} & $\mathrm{~b}$ \\
\hline & & 준비 중 & 71 & 4.23 & 0.816 & & $\mathrm{~b}$ \\
\hline & & 준비 예정 & 45 & 4.16 & 0.831 & & $\mathrm{~b}$ \\
\hline & & 취득의향 없음 & 16 & 3.63 & 0.824 & & $\mathrm{a}$ \\
\hline
\end{tabular}

${ }^{*} \mathrm{p}<.05,{ }^{* *} \mathrm{p}<.01$

분석 결과, 군특성화고 학생의 주특기 관련 자격증이 있는 학생들은 그렇지 않은 학생들보다 진로 개선 요구도가 통계적으로 유의미하게 높은 것으로 나타났다. 이를 구체적으로 살펴보면 군특성화고 학생의 중 주특기 관련 자격증이 있거나 준비 중 또는 준비 예정인 학생은 자격증 취득 의향이 없는 학생에 비해 진로 관련 개선 요구도(교사의 진로 관련 상세한 사전 정보 제공, 부사관의 직업적 안정성 확보, 장기부사관 임관 시 가산점 확대, 장기복무부사관 패스트트랙)가 높은 것으로 나타났다.

\section{2 군특성화고 학생의 교육과정 개선 요구도 및 희망 양성 분야}

\subsection{1 군특성화고 학생의 교육과정 개선 요구도}

군특성화고 교육과정 요구도에 대한 문항 중 학생의 일반특성 변인 중 통계적으로 
유의미한 차이를 보인 문항인 학생의 주특기 관련 자격증 소지 여부에 따른 분석 결과는 [표 4]와 같다.

분석 결과, 군특성화고 학생의 주특기 관련 자격증이 있는 학생들은 자격증 준비 의향이 없는 학생들보다 교육과정 개선 요구도가 상대적으로 높은 것으로 나타났다. 이를 구체적으로 살펴보면 군특성화고 학생의 중 주특기 관련 자격증이 있거나 준비 중 또는 준비 예정인 학생은 자격증 취득 의향이 없는 학생에 비해 교육과정 개선 요구도(장기복무 선발 기준에 맞춰 특화된 교육과정 운영, 지역군의 특성과 연계한 군 특기분야 역량 강화 교육과정 편성, 첨단과학기술병 양성을 위한 전문교과 강화, 주특기와 군복무 분야의 연계성 강화된 교육과정)에 대해 요구도가 통계적으로 유의미하게 높은 것으로 나타났다.

[표 4] 군특성화고 학생의 교육과정 개선 요구도 $<\mathrm{n}=615>$

[Table 4] ] Curriculum Improvement Needs of Mlitary-specialized Hgh Shools Sudent

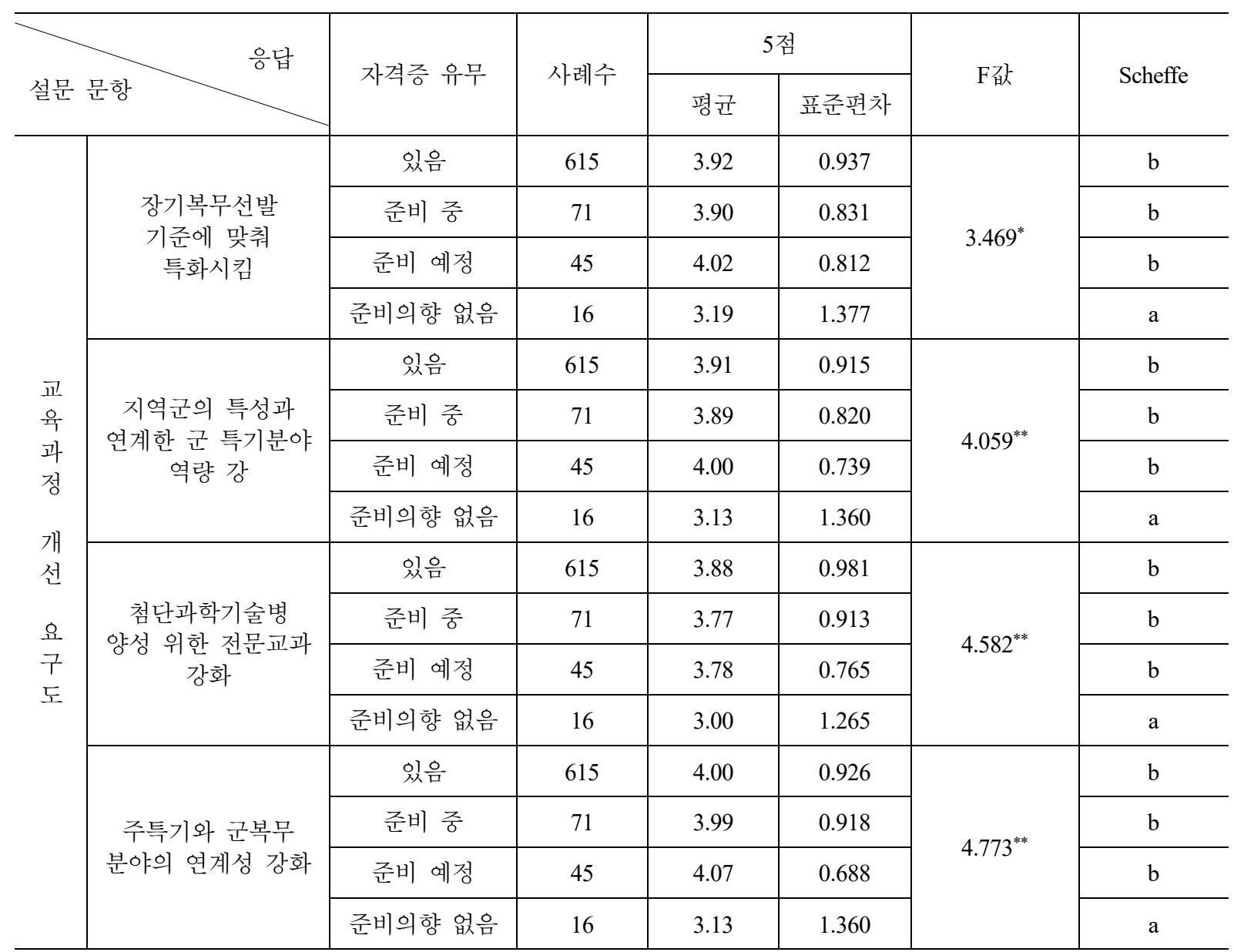

${ }^{* *} \mathrm{p}<.01$

\subsection{2 향후 희망하는 군특성화고 양성 분야}

군특성화고 학생이 현재의 주특기 분야 외 향후 필요하다고 생각하는 양성 분야(복수 응답)는 [표 5]와 같다. 즉, 드론(64.4\%), 인공지능(63.9\%)에 대한 응답 비율이 매우 높게 나타났고, 다음으로 로봇 $(42.4) \%$, 적층가공 $(12.9) \%$ 라고 응답하였다. 즉 학생들도 군 
군특성화고 교육과정을 통해 최근 기술 분야의 발전, 군인력 구조 변화와 관련이 있는 군 첨단기술 장비병 양성이 필요하다고 인식하고 있음을 확인할 수 있다.

[표 5] 군특성화고 학생의 향후 양성분야 대한 인식(복수 응답)

[Table 5] ] Military-specialized High Schools' Perception of Future Training Fields (Multiple answers are allowed)

\begin{tabular}{|c|c|c|c|c|c|c|c|c|c|c|c|}
\hline \multirow{2}{*}{ 구분 추가 양성분야 } & \multirow{2}{*}{ 사례수 } & \multicolumn{2}{|c|}{ 드론 } & \multicolumn{2}{|c|}{ 인공지능 } & \multicolumn{2}{|c|}{ 로봇 } & \multicolumn{2}{|c|}{ 적층가공 } & \multicolumn{2}{|c|}{ 기타 } \\
\hline & & $\mathrm{N}$ & (\%) & $\mathrm{N}$ & (\%) & $\mathrm{N}$ & (\%) & $\mathrm{N}$ & (\%) & $\mathrm{N}$ & (\%) \\
\hline 전체 & 747 & 479 & (64.1) & 477 & (63.9) & 317 & (42.4) & 96 & (12.9) & 19 & (2.5) \\
\hline
\end{tabular}

\section{5. 요약 및 결론}

본 연구를 통해 군특성화고 학생의 대부분은 졸업 후 장기 복무를 희망하고 있고, 이와 같은 진로 계획을 위한 진로 선택 및 교육과정 개선 요구도가 밀접 밀접한 연관성을 가지고 있음을 확인할 수 있었다. 이를 구체적으로 살펴보면 다음과 같다.

첫째, 군특성화고 학생의 진로 선택에 영향을 주는 요소 중 선택 시기는 고등학교 2 학년이 $54.4 \%$ 가장 많았으므로 2 학년 때 군특성화고(반) 운영 관련 정보 제공이나 다양한 체험의 기회를 제공할 필요가 있다. 그리고 진로 선택에 영향을 주는 사람은 교사가 $42.9 \%$ (군특성화고 교사 $23.5 \%$, 담임/부장교사 $19.4 \%$ ), 부모님이 $41.8 \%$ 로 나타났는데, 이러한 결과는 선행 연구 결과와 일치하였다[8][10][14]. 이를 통해 학생들이 진로 선택 시 교사를 매우 신뢰하고 특히 군특성화고 교사의 영향을 크게 받는 것으로 나타났으므로 교사들의 진로지도 관련 전문성 향상을 위한 제도가 필요함을 시사한다. 또한 학생들이 졸업 후 진로 경로에 대한 다양한 직업 정보 제공과 지속적으로 경력 개발을 통한 장기복무가 가능하도록 하는 방안이 필요하다.

둘째, 군특성화고 학생들의 진로 만족도는 4.05 로 매우 높았으며, 직업 군인이 되고 경제적으로 안정적인 삶을 유지하고 싶어 군특성화고를 선택하는 비율이 $68.3 \%$ 로 매우 높게 나타났다. 따라서 부사관으로서 임무 수행과 간부로서의 자질을 향상시킬 수 있도록 보다 나은 복무 여건을 마련하고, 장기부사관이 될 수 있는 패스트 트랙을 포함하여 다양한 경로를 개발할 필요가 있다. 또한 군특성화고 학생들은 사전에 군 복무과 관련한 다양한 정보 제공 등을 희망하는 것으로 나타났는데, 이는 직업정보 부족은 진로 결정에 부정적인 영향을 준다는 선행 연구 결과와 일치한다[6][9]. 특히 학생 중 주특기 관련된 자격증을 가지고 있거나 준비 중인 학생들의 경우 진로 개선 요구도가 매우 높은 것으로 나타났다. 최근 교육부의「직업계고 취업지원 방안」(2021.7.7)에서 발표한 군 자기개발비용 지원 대상을 (現) 병사 $70 \% \rightarrow 100 \%$ 로 확대 자격증 취득 지원, 자격증 실습 교육을 위한 집합 교육과정 등 제공[2]이 계획대로 실행되어 긍정적인 결과를 도출할 수 있도록 교육부와 국방부, 그리고 군특성화고 담당자들의 지속적인 관심이 필요하다.

셋째, 군특성화고 학생들은 교육과정과 관련해서 장기복무 선발 기준에 맞춰 특화된 교육과정 운영, 지역군의 특성과 연계한 군 특기 분야 역량 강화를 위한 교육과정 편성, 첨단 과학기술병 양성을 위한 전문교과 강화, 주특기와 군복무 분야의 연계성 강화된 
교육과정에 대한 요구도가 높은 것으로 나타났다. 이러한 결과는 특성화고에서 학생들이 산업체에서 요구하는 역량을 함양할 수 있는 교육과정, 이론과 실습을 연계한 교육과정이 중요하다는 선행 연구와 일치하는 것으로 나타났다[2][6][8][12]. 이와 같은 학생들의 교육과정 개선에 대한 요구를 반영하기 위해 현재 적용되고 있는 2021년 군특성화고 운영 지침을 [표 6]과 같이 개정(안)을 제안하고자 한다.

[표 6]「2021년 군특성화고 운영 지침」 신·구 대비표(안)

[Table 6] Comparison Between Old and New Military-Specialized High School Operation Guidelines

(Draft)

\begin{tabular}{|c|c|}
\hline 현 행 & 개정안 \\
\hline $\begin{array}{l}\text { 다. 학과편성 및 교육지원 } \\
\text { 1) 전문교과 과정은 군 기술교육과 일반 군사교육으로 } \\
\text { 구분하여 군특성화 교사에 의한 맞춤형 교육프로그램 } \\
\text { 을 운영한다. } \\
\text { 가) 군 기술교육: 과목의 중요도에 대한 가중치를 고려 } \\
\text { 하여 편성 } \\
\text { * 주당 } 10 \text { 시간 이상으로 구성, 전문교과 교육과정의 } \\
\quad 40 \% \text { 이상 유지 } \\
\text { 나) 일반 군사교육: 리더십, 체력단련, 안보현장 견학/ } \\
\text { 체험 등 } \\
\text { * 주당 } 2 \text { 시간 이상으로 구성, 리더십은 전문교과 과목 } \\
\quad \text { 으로 반영/교육·평가 }\end{array}$ & $\begin{array}{l}\text { 다. 학과편성 및 교육지원 } \\
\text { 1) 전문교과 과정은 군 기술교육과 일반 군사교육으로 } \\
\text { 구분하여 군특성화 교사에 의한 맞춤형 교육프로그램을 } \\
\text { 운영한다. } \\
\text { 가) 군 기술교육: 과목의 중요도에 대한 가중치를 고려하 } \\
\text { 여 편성 } \\
\text { * 주당 } \mathbf{2 0} \text { 시간 이상으로 구성, 전문교과 교육과정의 } \\
\underline{\mathbf{8 0 \%}} \text { 이상 유지 } \\
\text { 나) 일반 군사교육: 리더십, 체력단련, 안보현장 견학/체 } \\
\text { 험 등 } \\
\text { * 주당 } \frac{\mathbf{6} \text { 시간 이상으로 구성, 리더십은 전문교과 과목으 }}{\text { 로 반영/교육.평가 }}\end{array}$ \\
\hline $\begin{array}{l}3 \text { ) 군특성화 반은 고교 } 3 \text { 학년 과정에 학과를 편성하여 } \\
1 \text { 년 과정으로 보조사업을 지원 운영한다. } \\
\text { 가) } 3 \text { 학년(정과교육):일반 군사교육 및 군 기술교육(주 } \\
12 \text { 시간 이상) } \\
\text { 나) } 1.2 \text { 학년(자율시행):일반 군사교육(리더십, 체력단련, } \\
\quad \text { 안보현장견학 등) - 중략- }\end{array}$ & 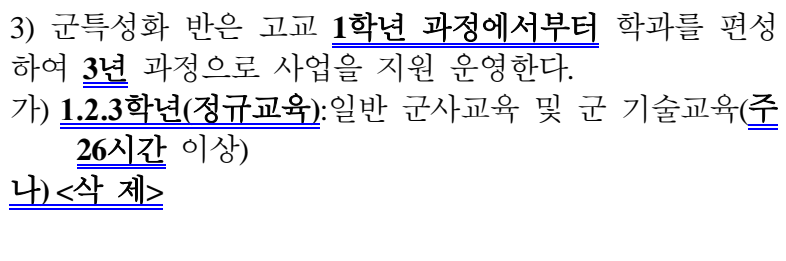 \\
\hline $\begin{array}{l}\text { 4) 교재(교과서 등)/교보재는 연간 교육시간과 주특기, } \\
\text { 해당 학교의 특성 등을 고려하여 각 군특성화고등학교 } \\
\text { 장 주관하 제작및활용, 보충교재 개발도 각 군 및 군 } \\
\text { 병과학교의 지원을 받아 자체 제작 활용한다. } \\
\text { * 각 군은 실습에 필요한 기자재(불용장비, 보충교재, } \\
\text { 교보재) 등을 적극 발굴 지원한다. }\end{array}$ & $\begin{array}{l}\text { 4) 교재(교과서 등)/교보재는 연간 교육시간과 주특기, 지 } \\
\text { 역거점의 군과 연계된 학교의 특성 등을 고려하여 각 군 } \\
\text { 특성화고등학교장 주관하 제작및활용, 보충교재 개발도 } \\
\text { 각 군 및 군 병과학교의 지원을 받아 자체 제작활용한 } \\
\text { 다. } \\
\text { * 각 군은 실습에 필요한 장비 및 자재(불용장비, 보충교 } \\
\text { 재, 교보재)를 학교장의 감독하에 교보재로 적극 지원한 }\end{array}$ \\
\hline
\end{tabular}

먼저 전문 교과의 절대적 시간이 부족하고 과목수 등이 부족하다는 문제점이 제기되고 있으므로 [표 6]의 1)항, 3)항의 내용을 일반 군사교육과 군 기술교육을 $1,2,3$ 학년 정규 과정으로 확대하여 운영 [(現)3학년 1년 동안 시행] 하도록 하고, 군 기술교육은 주당 20 시간 이상으로 구성[(現) 주당 12 시간 이내]하고, 관련된 주특기 분야 기술 관련 능력을 향상시키기 위해서는 전문교과의 $80 \%$ 이상으로 유지하도록 할 필요가 있다. 그리고 일반 군사교육의 경우는 주당 6 시간 이상으로 확대하도록 개정하여 군특성화고 학생들의 전문성을 제고할 수 있도록 교육과정을 편성.운영할 필요가 있다. 그리고 4항)은 교재(교과서 등)/교보재의 경우 시간, 주특기, 지역거점의 군과 연계된 학교 특성을 고려하여 학교장의 감독하에 지원하도록 개정하여 실제 군에서 요구하는 역량을 함양할 
수 있는 교육과정의 기반을 마련할 수 있는 방안을 제시하였다.

\section{References}

[1] S. J. Lee, Y. J. Hur, M. R. Lee, K. W. Song, Y. J Kim, S. H. Park, A Plan to Improve the Operation of Military Specialized High Schools, Korea Research Institute for Vocational Education \& Training, pp.100-101, (2021), https://www.krivet.re.kr/ku/da/kuBAAVw.jsp?gn=E1-E120210190

[2] Collaboration of ministries concerned, The 12th Ministerial Conference on Social Relations and the 4th Conference on Human Investment Talent Development [Attachment. Agenda No. 1], Plan for inspection and improving policies on employment support for vocational high schools, https:/www.moe.go.kr/boardCnts/viewRenew.do?boardID=294\&boardSeq=84950\&lev=0\&searchType=null\&status $\mathrm{YN}=\mathrm{W} \&$ page $=28 \& \mathrm{~s}=$ moe\&m $=020402 \&$ opType $=\mathrm{N}$, July 7 (2021)

[3] 2021 Specialized High School Military Support Project Operation Plan, Ministry of National Defense, pp.1-2, (2021)

[4] https://kookbang.dema.mil.kr/newsWeb/20190829/5/BBSMSTR_000000010021/view.do, Jan 20 ( 2021)

[5] H. S. Park, K. D. Nam, A study on the recognition of job competence and job satisfaction of joint industry-academy teachers in the military Specialized High School, (2019), Vol.38, No.5, pp.1-22, DOI: 10.37210/JVER.2019.38.5.1

[6] H. S. Park, A Study on the implementation of high school graduates of military service Military Technology Workforce, The Journal of Sciences and Arts, (2014), Vol.2014, No.S-8, pp.145-164.

[7] H. K. Kim, J. H. Kim, Y. H. Kim, Why do vocational high school students want to pursue college education upon graduation?, Korea Society, (2017), Vol.18, No.2, pp.35-69, DOI: 10.22862/kjsr.2017.18.2.002

[8] J. Y. Ahn, A Study on the Status, Performance, and Career Decision for Employment of Students from Korean Apprenticeship High School, The Journal of Vocational Education Research, (2019), Vol.38, No.5, pp.47-78, DOI: 10.37210/JVER.2019.38.5.47

[9] M. H. Lee, An Analysis of the Structural Relationship among Variables Influencing Career Decision of Specialized High School Students, The Korean Journal of Technology Education, (2016), Vol.16, No.2, pp.149-166, UCI: G704001559.2016.16.2.002

[10] S. Y. Oh, A Study on vocational high school students' perspective on their career decision making: focusing on Seoul area, The Journal of Vocatioanal Education Research, (2012), Vol.31, No.3, pp.135-151, UCI: G704000975.2012.31.3.005

[11] C. J. Lee, Student perception survey analysis for improvement of specialized high school curriculum, 2022 Revision Curriculum-Related Consecutive Discussion Materials, pp 1-61, (2021)

[12] S. J. Lee, S. T. Kim, I. Y. Kim, J. Y. Kim, K.W. Song, C. H. Lee, Performance management and improvement plan, Apprenticeship at Vocational High Schools in Korea 2020, Korea Research Institute for Vocational Education \& Training, pp.160-172, (2021), https://www.krivet.re.kr/ku/da/kuBAAVw.jsp?gn=E1-E120210183

[13] 2021 Specialized High School Military Support Project Operation Plan, Ministry of National Defense, pp.7-16, (2021)

[14] M. S. Kang, A study on career decision network of specialized high school students, The Journal of Career Education Research, (2021), Vol.34, No.1, pp.1-23, DOI: 10.32341/JCER.2021.3.34.1.1 